\title{
REPORT
}

\section{Teaching Business Looking at the Support Needs of Instructors}

December 12, 2019

Kurtis Tanaka

Danielle Cooper

Nora Allred

Natasha Arguello

Brian Bourke

Nicole Branch

Cara Cadena

Danielle Colbert-Lewis

Sarah Edmonds

Preethi Gorecki

Karen Grimwood

Marianne Hageman

John Heintz

Ashley Ireland

Jon J effryes

Patricia Kenly
Louise Klusek

Andrea Koeppe

Vera Lux

James Mellone

Ximin Mi

Lauren Movlai

Livia Olsen

Ryan Phillips

Anthony Raymond

Linda Rich

Veronica Rodriquez

Peter Rogers

Erin Rowley

Jenn Sams
Carol Sánchez

Edith Scarletto

Jamillah Scott-Branch

Melanie Sellar

Kendra Spahr

Dana Statton Thompson

Charles Terng

Edward F. Wall III

Heather Williamson

Qiong Xu

Ann Zawistoski

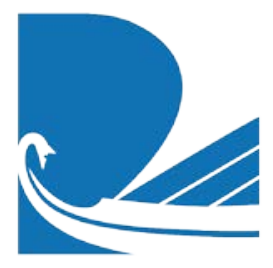

ITHAKA S+R 


\section{ITHAKA S+R}

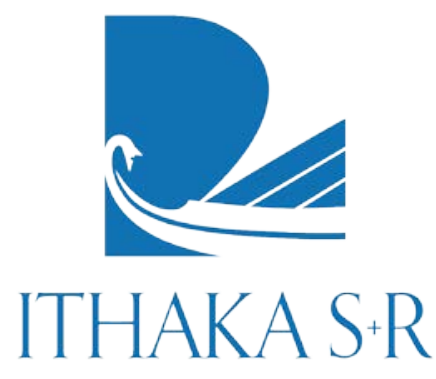

Ithaka $S+R$ provides research and strategic guidance to help the academic and cultural communities serve the public good and navigate economic, demographic, and technological change. Ithaka $\mathrm{S}+\mathrm{R}$ is part of ITHAKA, a not-for-profit organization that works to advance and preserve knowledge and to improve teaching and learning through the use of digital technologies. Artstor, J STOR, and Portico are also part of ITHAKA.
Copyright 2019 ITHAKA. This work is licensed under a Creative Commons Attribution-NonCommercial 4.0 International License. To view a copy of the license, please see http://creativecommons.org/licenses/by-nc/4.0/.

ITHAKA is interested in disseminating this brief as widely as possible. Please contact us with any questions about using the report: research@ithaka.org. 


\section{Table of Contents}

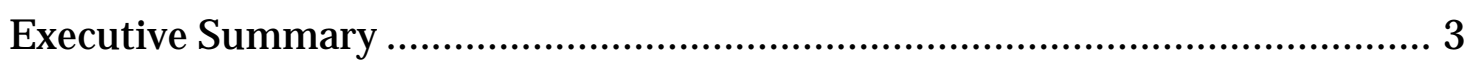

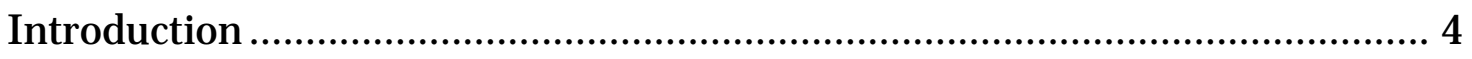

Course Development and Material Creation ......................................................... 9

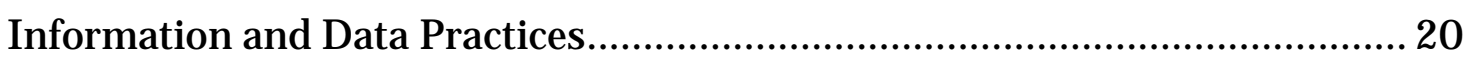

Leveraging Technology in the Business Classroom ........................................... 30

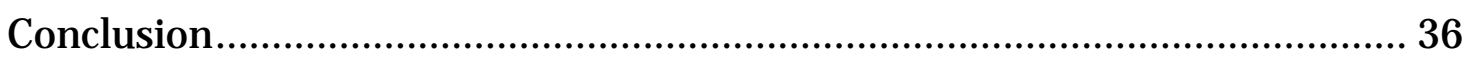

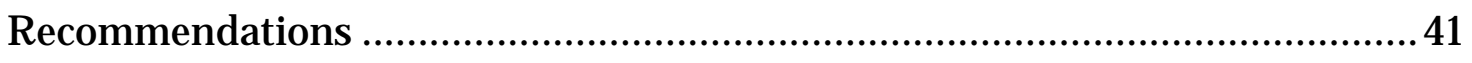

Appendix 1: Research Teams and Local Reports ........................................... 46

Appendix 2: Semi-Structured Interview Guide............................................... 49

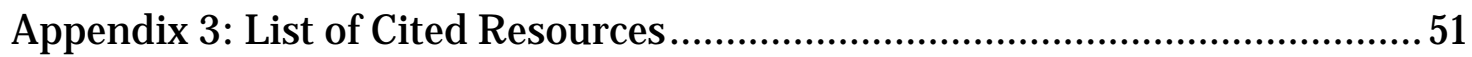




\section{Executive Summary}

In 2018, Ithaka S+R began a new research program investigating scholars' undergraduate teaching practices. As a first foray in this program, we looked at the teaching practices and needs of instructors teaching in business and business related disciplines. The project was undertaken collaboratively with research teams at 14 academic libraries in the United States and we thank those institutions and their researchers for partnering with us.

Business represents the most popular undergraduate major at American colleges and universities and was seen as the ideal discipline to begin with, especially as the potential number of students to be positively impacted is correspondingly large. The goal of this report, therefore, is to provide actionable findings for organizations, institutions, and professionals who support the teaching practices of business educators. This report describes the teaching practices of business instructors, both those that are common to all college level instruction as well as those that are distinctive of undergraduate business instruction. In doing so, we isolate how these practices can inform the strategic decisions of academic libraries, universities, technology providers, and others. We group our findings and recommendations around the following key challenges:

- Identifying appropriate course content. Instructors struggle with finding resources, especially cases, that are current and appropriate for their students, and so often invest significant amounts of their time creating their own content. There exists significant opportunity to better leverage these materials by creating opportunities and incentives to share this content openly.

- Finding, accessing, and working with data. As data becomes a societal watchword, the private sector is in increasing need of employees that have a high level of data literacy. Yet significant barriers exist for both instructors and students in finding and accessing data, especially industry and financial data.

- The promise and peril of learning technologies. Instructors constantly struggle to keep their students engaged and have increasingly turned to learning technologies to help manage their student's attention spans. These technologies often collect data on students, yet instructors were deeply ambivalent about the potential of learning analytics to support their teaching.

- Concerns over costs. Instructors are increasingly mindful of the costs incurred by their students, either through the necessity of buying textbooks and cases, or technologies like clickers or software licenses. However, they are generally not aware of recent movements toward open access resources or zero-cost textbooks that could alleviate these concerns. 


\section{Introduction}

In 2018, Ithaka S+R gathered representatives from 14 libraries to understand how undergraduate business instruction can be better supported. This is the first in a series of projects that will examine teaching practices (as opposed to research practices), in an effort to identify the range of support scholars need across their academic responsibilities. Investigating the teaching practices and concerns of business instructors has proven an illuminating first foray in this series. While, in some respects, students are students regardless of discipline, as business education developed over the past century, it also came to be distinguished by several unique practices and emphases that gave rise to unique needs, and hence, unique supports.

An arriviste in the millennium long history of the university, the business school (or school of management) rose to its current prominence over the course of the 20th century. Building off European innovations in the teaching of management principles, the first American business school was the University of Pennsylvania's Wharton School, founded in 1881. Subsequently, a host of business schools was founded elsewhere in the opening years of the 20th century, with nearly 200 established by $1936 .{ }^{1}$ Innovations in business instruction soon followed. American publishing houses (e.g. Richard D. Irwin Publishing, now an imprint of McGraw-Hill) began to produce dedicated textbooks and the Harvard Business School pioneered and popularized the case study method by $1920 .{ }^{2}$ These twin innovations, as well as the expansion of business schools across the country and then the world, placed a distinctly American imprint on business education, despite its European origins. Today, there are more than 500 business schools in the United States alone, and, by some estimates, thousands more across the globe. ${ }^{3}$

Hundreds and thousands of business schools mean a lot of business instructors and business students teaching, learning, and in need of support. Recent developments have made this need especially acute. The 2008 financial crisis led many to criticize business schools, from both within and without, for inculcating a culture of greed and loose

${ }^{1}$ Howard Thomas, Peter Lorange, and Jagdish Sheth, The Business School in the Twenty-First Century: Emergent Challenges and New Business Models (Cambridge: Cambridge University Press, 2013), p. 3, doi:10.1017/CBO9781139012119.

2 Robert Klonoski, "The Case for Case Studies: Deriving Theory From Evidence," Journal of Business Cases, May/June 2013, https://clutejournals.com/index.php/JBCS/article/view/7805.

${ }^{3}$ See list of AACSB member schools (https://www.aacsb.edu/accreditation/accreditedschools?F_Accreditation=Business\&F_Country=United+States), also Martin Parker, Shut Down the Business School: What's Wrong with Management Education (London: Pluto Press, 2018), p. 12. 
ethics. ${ }^{4}$ Silicon Valley and the disruption economy has further put pressure on the business school's ability to keep up with the increasing pace of change in the private sector, and even old pedagogical orthodoxies, such as the Harvard hallowed case study, are now coming up for debate. While business is the most popular undergraduate major in the United States, enrollment in MBA programs in the US has markedly declined in recent years, and new, one year MBAs, more standard in Europe, are slowly beginning to take off in the US as well. 5

\section{As transformations in the business sector, such as artificial intelligence, automation, and big data are driving innovations in how business is taught, academic libraries are also in the process of re-imagining how to best support their institutions' mandates to prioritize student success, in which effective pedagogy is a critical element.}

The current study focuses on undergraduate classroom instruction, where the time is no less ripe for a critical assessment of business instructors' teaching needs and the development of informed and innovative support services. Business education often incorporates dynamic pedagogical approaches such as technological experimentation, partnerships with industry, and collaborations with diverse communities. As transformations in the business sector, such as artificial intelligence, automation, and big data are driving innovations in how business is taught, academic libraries are also in the process of re-imagining how to best support their institutions' mandates to prioritize student success, in which effective pedagogy is a critical element. Our report therefore explores the entirety of business instructors' teaching activities, from course planning to industry partnerships, as well as their perceptions of the most pressing challenges in teaching business students today. We share our findings and recommendations to

\footnotetext{
${ }^{4}$ Martin Parker, Shut Down the Business School: What's Wrong with Management Education (London: Pluto Press, 2018$)$, p. 14.

${ }^{5}$ See discussion in Johann N. Neem, "Abolish the Business Major!: Anti-Intellectual Degree Programs Have No Place in Colleges," The Chronicle of Review, August 13, 2019, https://www.chronicle.com/interactives/2019-08-13-abolish-the-business-major. See also John A Byrne, "MBA Apps Take a Shocking Plunge," Poets \& Quants, August 29, 2018, https://poetsandquants.com/2018/08/29/mba-apps-take-a-shocking-plungel; and Seb Murray, "Will One Year MBAs Take off in the US?" FindMBA, August 13, 2019, https://find-mba.com/articles/will-one-year-mbas-take-off-in-the-us.
} 
highlight opportunities for various stakeholders to better support business education at this critical time of change.

\section{Methods}

Over the past five years, Ithaka $\mathrm{S}+\mathrm{R}$ has fielded numerous cohort-based research projects investigating the research practices of scholars across a variety of fields, including Civil \& Environmental Engineering, Agriculture, Chemistry, Asian Studies, Religious Studies, Public Health, and Indigenous Studies. ${ }^{6}$ This report is the capstone to the first of Ithaka S+R's projects in the Teaching Support Services program, and, like the previous Research Support Services projects, it takes a faculty-centered approach. By focusing on scholars' teaching practices, we are better able to understand both the common struggles instructors face in their classrooms, as well as the unique challenges inherent in instruction in particular disciplines or pedagogical approaches.

Participation in the project was open to any higher education institution with a business education program that was able to conform to the project specifications (e.g. timeline and research capacity). A diverse group of 14 academic institutions ultimately elected to participate in the cohort. Appendix 1 lists the participants on the institutional research teams. We thank all the institutions that participated in the project.

The partner libraries created research teams of one to four members who, following a training workshop designed and led by Danielle Cooper, collected the qualitative data that Ithaka S+R analyzed for this report. The research teams at the participating institutions primarily comprised subject librarians but also included participants in other roles, such as those with capacities in data services, assessment, and instruction more broadly. Each team conducted research with approximately 15 instructors teaching in Business (we give our definition of "business instructor" below) at the undergraduate

\footnotetext{
6 Jennifer Rutner and Roger C. Schonfeld, "Supporting the Changing Research Practices of Historians," Ithaka S+R, 7 December, 2012, https://doi.org/10.18665/sr.22532; Matthew Long and Roger C. Schonfeld, "Supporting the Changing Research Practices of Chemists," Ithaka S+R, 25 February 2013, https://doi.org/10.18665/sr.22561; Matthew Long and Roger C. Schonfeld, "Supporting the Changing Research Practices of Art Historians," Ithaka S+R, 30 April 2014, https://doi.org/10.18665/sr.22833; Danielle Cooper et al., "Supporting the Changing Research Practices of Religious Studies Scholars," Ithaka S+R, 8 February 2017, https://doi.org/10.18665/sr.294119; Danielle Cooper et al., "Supporting the Changing Research Practices of Agriculture Scholars," Ithaka S+R, 7 June 7 2017, https://doi.org/10.18665/sr.303663; Danielle Cooper et al., "Supporting the Changing Research Practices of Public Health Scholars," Ithaka S+R, 14 December 2017, https://doi.org/10.18665/sr.305867; Danielle Cooper et al., "Supporting the Changing Research Practices of Asian Studies Scholars," Ithaka S+R, 21 June 212018 , https://doi.org/10.18665/sr.307642; Danielle Cooper et al, "Supporting the Changing Research Practices of Civil and Environmental Engineering Scholars," Ithaka S+R,16 January 2019, https://doi.org/10.18665/sr.310885; Danielle Cooper et al, "When Research is Relational: Supporting the Research Practices of Indigenous Studies Scholars," Ithaka S+R, 11 April 2019, https://doi.org/10.18665/sr.311240.
} 
level through semi-structured interviews. These interviews followed an interview guide developed by Ithaka S+R that followed the arc of the teaching process. Instructors were asked about their teaching experience, their methodologies and approaches, as well as the materials they create and the resources they rely on to effectively engage their students (see Appendix 2 for the interview guide). Each team then developed its own analysis from the data it collected at its respective institution with the option of either creating an internal whitepaper or a publicly available local report. The publicly available local reports, which provide a complement to this capstone report, are listed and linked in Appendix 1.

Ithaka S+R collected anonymized transcripts from the 158 interviews conducted across the participating institutions. We selected 40 of these transcripts as a representative sample based on the research subfields delineated below, position title, and institution. The sampled transcripts were analyzed through a grounded approach to coding utilizing NVivo software. The interviewees remain unidentified in this report to protect anonymity. We thank the interviewees for their participation.

We want to acknowledge and thank Lisa J anicke Hinchliffe, Mark McBride, and Roger Schonfeld for providing feedback on the report and its findings.

\section{Defining the Business Instructor}

This report focuses on the teaching practices and needs of business instructors at higher education institutions. We defined "business instructor" to mean any individual teaching in business or related disciplines as the primary instructor of record. The word "instructor" is used because it is important to acknowledge that business instruction may often be performed by "practitioners," who may not belong to the permanent faculty of an institution. Though we did not intentionally sample interviewees to be able to separate out the unique needs of practitioners (if any) in our analysis, it is notable that, at least for the practitioners who were interviewed, the challenges they identified were not radically different from those of the permanent faculty.

\section{Educators in business believe they must be responsive to the evolving needs of businesses, and this drives the emphasis on teaching practical skills and information.}


Business education is typically, though not always, instantiated in its own school, often in its own building or buildings, and so structurally separate from other constituent schools such as arts and sciences. Additionally, students must often apply separately to the business school, sometimes in their freshman year to start their sophomore year in the Business School. This separation can be significant, as students enrolled in the school of business often have access to certain resources not available to the rest of the campus (e.g. Bloomberg terminals or market databases). Instructors may also have appointments across schools and departments in allied disciplines such as economics or statistics, and student interdisciplinarity beyond such closely related fields is valued by industry partners. ${ }^{7}$ Nonetheless, the main concern of business school curricula is to instill in students an understanding of, and functional ability in, core business operations, such as management, accounting, finance, or marketing. While several academic fields maintain ties to industry, the relationship between business schools and the private sector is especially close. Educators in business believe they must be responsive to the evolving needs of businesses, and this drives the emphasis on teaching practical skills and information. Because business schools often position themselves as the producers of the business leaders of tomorrow, business pedagogy also places a strong emphasis on developing both leadership and teamwork skills, though developing a curriculum that teaches both "hard" and "soft" skills, and in the right balance, is often a challenge.

For the purpose of creating a sample of business instructors that reflected the variation in teaching responsibilities, this project classed instructors according to the following common subfields of business education:

- Accounting

- Business Law \& Ethics

- Entrepreneurship

- Finance \& Economics

- Information Systems \& Statistics

- International Business
- Management

- Marketing \& Communications

- Operations \& Supply Chain Management

- Organizational Behavior \& Human Resources

${ }^{7}$ Business Education Jam, 2014 Final Report, 2015, p. 8, http://questromworld.bu.edu/businesseducationjam/files/2015/04/Business-Education-Jam-Envisioning-the-Future.pdf. 
It is, of course, necessary to remember that while such categorizations are heuristically useful for analysis, they do not necessarily capture the complexity of the subjects instructors may teach in their classes. For example, instructors may teach across closely related fields such as economics and statistics, while instructors that focus on entrepreneurship may, because of the nature of the entrepreneurial endeavor, teach different aspects of all of these categories. Likewise, numerous commonalities exist across these teaching areas: the use of case studies is one especially prominent example, as is a reliance on data and databases. It is also important to note that students may take a variety of paths into one of these fields, and, unlike in conducting their own research, instructors must account for a wide variety of student backgrounds and skill levels, and adjust their teaching accordingly.

\section{Course Development and Material Creation}

As the business world constantly changes, so too must the texts instructors teach, and this need to stay current poses a significant challenge. Instructors face numerous hurdles in designing, creating, and finding such content for their courses, and as the central feature of business pedagogy is the case study, finding or creating current cases appropriate for undergraduate classes is one of the most essential, though often challenging, elements of course design. Finding the right textbook can be equally difficult, but instructors have developed a number of strategies to ameliorate these challenges. In particular, a small but growing awareness of open access resources, for example, OERs (Open Educational Resources), holds tremendous potential to address several of these problems. Indeed, instructors are increasingly relying on diverse resources beyond textbooks to customize the materials their students will engage with in their classes. Given the popularity of the business major, movement towards no or low cost resources in this field has the potential to make a significant impact for both instructors and students.

\section{Instructors are increasingly relying on diverse resources beyond textbooks to customize the materials their students will engage with in their classes.}

\section{Course Development}

Instructors develop a wide variety of course materials for their classes. Most interviewees noted that a syllabus was the central document created in the process of course development. Syllabi may be generated entirely from scratch, though newer instructors, 
or instructors teaching a class for the first time, often rely on syllabi provided by their departmental peers as starting points. While instructors often have significant leeway in the running of their classes, numerous interviewees noted that occasionally syllabi were developed at the department or specialty-wide level, especially for introductory classes.

Most interviewees cited colleagues within their home departments as important resources for the development of their own pedagogy. In addition to the development of syllabi, instructors may rely on their departmental peers to suggest course materials or share their experiences with novel technologies, such as Kahoot!. ${ }^{8}$ This support is especially significant as the sharing of course materials (such as syllabi) beyond the department or confines of the institution does not appear to be a widespread practice in business education. Interviewees rarely mentioned searching the internet or reaching out to instructors beyond their institution to request syllabi or other course materials, nor did they recall anyone requesting such material from them. The use of networking tools such as Facebook groups, personal websites, or blogs to crowdsource teaching materials was not significantly prevalent across the interviewee cohort. This is not to say that business instructors are opposed to sharing their course materials more widelyindeed, some interviewees noted they would share materials if asked-but this does not appear to be a significant element of course development for many instructors at present.

Many interviewees shared that, while course development is generally carried out by the instructor, or in concert with the instructor's department, those teaching courses requiring student research may coordinate with their business librarian to plan a class session on library resources and research practice. However, though collaboration with the library to plan assignments or research projects did not generally progress any deeper than this, more extensive collaboration may yield significant benefits to instruction. As the case study is a central element of business instruction, ensuring that instructors are aware of the library's resources may aide them in selecting topics better aligned with the resources available at their institution. This is especially true of courses involving access to databases (discussed in more detail below), where securing access to relevant data sources is critical for student learning. Closer collaboration, or at least keeping instructors aware of resources and databases useful for instruction, has the potential to set students up for success as they begin to conduct research.

Institutional resources, such as centers for teaching and learning (CTL), can also play an important role in course development. Several interviewees reported attending seminars

\footnotetext{
${ }^{8}$ Kahoot! is a game based leaning platform accessible by web browser, phone, or app. See Appendix 3 for a list of technologies used for business instruction mentioned in this report.
} 
held by their institution's CTL to improve their teaching or to learn about new teaching methodologies and technologies. Some institutions offer seminars specifically targeted at business instructors, such as on teaching the case study method, or provide instructional designers specifically assigned to the business school. In addition to these on-campus resources, instructors may also take courses through external associations like the Association of College and University Educators (ACUE) to improve their teaching. Likewise, Harvard Business School (HBS) offers seminars for instructors teaching in business at degree granting institutions (as opposed to corporate trainers, for example). Data providers, such as Bloomberg or Eikon, also offer their own training programs that may be useful for instructors using these tools. One caveat for these resources is expense, as one interviewee noted about the HBS courses, "[those classes] are outrageously expensive [and] I haven't really found a good conference for that kind of thing either."

Finally, many instructors teach online versions of their classes and in these cases, developing separate course and lecture materials geared for the online environment could prove a challenge. Most notably, many interviewees said that they record lectures as part of their online course development. Recordings could be video or audio, but in either case, instructors often expressed frustration at the recording process. As instructors do not generally have training in recording or video editing, many were concerned about the quality and professionalism of their materials. Some, for example, simply record at home or in their office rather than in a studio, or simply use their computer's built in microphones and cameras to record themselves. Other instructors use platforms such as Panopto to record and distribute their content, but interviewees were not always sure if they had access to this platform through their institution. Systems like Panopto, were, however, especially desired by instructors, as they were concerned about the spread of their video or audio materials to YouTube or the internet more generally. Advising instructors of on-campus resources to aid in this kind of material creation and content control has the potential to improve this process quite dramatically and cut down on instructor workload and concerns.

\section{Case Studies}

The case study is a distinctive element of business education, and a majority of interviewees, from those teaching marketing to accounting to ethics, reported using the case method in at least some of their teaching. Since business pedagogy tends to focus on practical knowledge, the case method is dominant because it is believed to be a valuable kind of experiential learning through which students can sharpen and apply their 
problem solving and critical thinking skills. ${ }^{9}$ However, the extent to which case studies are used in a course depends on a number of factors; for example, senior capstone courses tend to be virtually all case work, while introductory classes may use cases more sparingly. Different schools may also have different pedagogical traditions. Instruction at the Harvard Business School and the Ivey School of Business, for example, tends to be primarily case based, and often serves as a model for other business schools. Indeed, curricula modeled on these schools' approaches may feature on average 10-12 cases per course. ${ }^{10}$

Instructors recognize that there are many ways to teach a case study, but generally wish they had better resources to explore other pedagogical approaches. For example, when one instructor was asked what would be the most useful area to provide instructional support they answered, "any[thing] case-based, that's just something that anytime I can gain exposure on how other people do them [it is useful] because it seems like there's a broad range of that." Such supports do exist, for example one interviewee recalled attending a "boot camp" where they practiced teaching cases to a variety of students and student levels. Harvard Business School also offers such training but, as noted above, these programs can be prohibitively expensive. Thus, while opportunities to explore other case method pedagogies exist, instructors may face barriers to exploiting these opportunities depending on their institutional or professional resources.

\section{Some instructors express difficulties finding cases appropriate for their class schedules or their student's abilities, and so discovering appropriate case studies for their classes can be a difficult, though essential, element of course design.}

The use of cases can unfold in a variety of ways in the classroom. Instructors may walk their class through a single case over the course of a class session, or assign one case for

\footnotetext{
${ }^{9}$ For the history and theory behind the case method see Robert Klonoski, "The Case For Case Studies: Deriving Theory From Evidence," Journal of Business Cases, May/June 2013, https://clutejournals.com/index.php/JBCS/article/view/7805.

10 Nitin Nohria and Jan W. Rivkin, "The Case for Cases," BizEd, August 30, 2018, https://bized.aacsb.edu/articles/2018/09/the-casefor-cases.
} 
students to work through over the course of one to two weeks. Instructors may also assign groups of students to take deeper dives into cases and assign them as projects of several weeks' duration in the course of a semester, and this project-based approach, case based or not, is quickly gaining traction in business education. ${ }^{11}$ Each type of assignment naturally requires differing levels of student skill and support. At the project level, students are most likely to perform in-depth qualitative and quantitative research, and therefore require the most support. Discussion of student research needs will be discussed in greater detail below; here it is sufficient to point out that while case studies can be assigned at a range of timescales and levels of analysis, not every case is suitable for every assignment. Some instructors express difficulties finding cases appropriate for their class schedules or their student's abilities, and so discovering appropriate case studies for their classes can be a difficult, though essential, element of course design.

A few major publishers dominate the provision of case study materials. Harvard Business School (HBS), the Ivey School of Business, and McGraw Hill were the most cited providers. Interviewees share how this dominance can be problematic, however. The cost of materials provided by these publishers was a concern, and the expense of these materials can pose a significant hurdle to instructors and students at less wealthy institutions, and those serving less advantaged student populations. Finding cases designed for undergraduates (as opposed to MBAs), or different levels of undergraduates, was also a challenge, and several interviewees noted they rewrote cases to be suitable for their classes. As one instructor explained, "Finding a case that would fit right into the classroom experience can be difficult in figuring out [how] best to tailor it. Sometimes cases are written especially for issues [at] more of a graduate level, and to tailor it to an undergraduate experience and fit it into a 50- or 75-minute class can be challenging." Furthermore, publishers may not offer strong cases in all areas of business instruction. For example, one interviewee noted that HBS tended not to publish cases useful for data analytics courses, and therefore cases had to be sourced widely (access to data is a separate issue and will be addressed below). Finally, because the cases provided by these publishers are so widely used, there was concern that students could easily find answers or guides online, and even that rewritten cases could be quickly posted online, thereby severely limiting the reusability of these materials.

Instructors may try to circumvent or alleviate these problems by collecting or creating their own archive of case studies to assign their students. ${ }^{12}$ As noted, some instructors may rewrite case studies to better suit their needs, while others may write cases more or

11 Kerry Laufer, Shannon McKeen, and Micellana Jester, "Taking Measure of Experiential Learning," BizEd, January 3, 2018, https://bized.aacsb.edu/articles/2018/january/taking-measure-of-experiential-learning.

${ }^{12}$ See Danielle Cooper and Oya Rieger, "Scholars ARE Collectors: A Proposal for Re-thinking Research Support," Ithaka S+R, November 2018, https://sr.ithaka.org/publications/scholars-are-collectors/. 
less from scratch. The writing and tailoring of cases requires a significant investment of time on the part of the instructor, as one interviewee explained, "I have some cases that I'm thinking of doing. I have sabbatical in the spring. That's something that I'm going to be working on when I'm gone - writing the case of my own." If writing from scratch, instructors may need to search for the necessary background information and, perhaps most difficult, find the requisite industry data. Instructors can spend days or weeks at a company, conducting interviews and learning about the organization in order to write a case study about it. Instructors may alleviate these problems by writing cases in their own area of research and using their own research data. Nonetheless, developing cases requires a significant investment of an instructor's time and resources, and even when making this investment, some instructors wished for more established mechanisms by which they could vet their work and make sure the case is complete, accurate, and appropriate for their students.

\section{"I've used free cases and they're not always the strongest, especially because it takes a while to find cases that freshmen can digest."}

Finding published cases beyond the major providers can also be a challenge. Venues for instructors to share cases they have created certainly exist, and some interviewees noted they utilized these resources. Several publications like the J ournal of Business Cases and Applications (J BCA) or Issues in Accounting Education, for example, publish these resources, some open access, others requiring a subscription. However, not all resources are created equal. Quality was a concern regarding free resources. As one interviewee noted, 'I've used free cases and they're not always the strongest, especially because it takes a while to find cases that freshmen can digest." Free cases are often likely to be older and so less relevant to current business practices and concerns. The sharing of such resources does not yet appear to be at a level significant enough to provide an easy alternative to HBR or McGraw Hill, though there seems to exist an unoccupied niche in cases pitched at a lower undergraduate level. As a result, instructors face significant hurdles in discovering appropriate and usable material, even when not writing cases from scratch.

\section{Textbooks}

As with case studies (and there is certainly overlap), textbooks were often critiqued for not staying current or not being sufficiently oriented towards practical information. In 
cases where publishers do keep texts up to date, pressure is then exerted on students to buy the newest version of the text, creating a significant financial burden. Such criticisms are not, of course, unique to business textbooks. However, as business education must respond not just to the steady advance of scholarship but to industry forces as well, the problem can be especially acute. The pace of change places a constant demand on instructors to develop their own content, perhaps only assigning a textbook as an optional reference. Owing to these pressures, there is no perfect, one size fits all textbook, and, as a result, instructors overwhelmingly preferred working with publishers who would allow them to pick-and-choose chapters to include in a course bundle or bespoke textbook. Cost was similarly a concern in the decision to assign a textbook, and the move to specially assembled bundles seems a response to student frustration at buying a textbook only to be assigned a small portion of it.

The option to select desired chapters from a publisher's stock of materials is a significant benefit to instructors when designing their courses. Some instructors also noted that texts may be used by multiple courses simultaneously, and therefore portions of the textbook may be covered in different classes (though this may be a frustration for students not taking both classes). Finally, some instructors took a much longer view of textbook use, seeing them not as an instructional aide for coursework, but as a resource students can and should return to in their future professional lives. Of course, some texts lend themselves to this kind of long-term use better than others. The HR Book of Knowledge, for example, is a standard text for the Human Resources profession and students can later use it as a reference to prepare for certification exams.

As the Human Resources example makes clear, different sub-disciplines treat textbooks quite differently, and require very different things of them. Accounting, for example, may rely quite extensively on a textbook, but also incorporate case studies, database, and lab work, and so platforms like Connect are especially useful. On the other hand, Business Law and Ethics instructors may rely much more heavily on academic articles and textbooks that are more philosophical anthologies than how-to manual. Likewise, fields subject to frequent change, like Entrepreneurship, World Economy, or Information Systems, may not rely on textbooks at all, or only in a supplemental capacity. However, even within these broad divisions, textbook use can vary widely. The extent to which instructors use a textbook may, therefore, be more a function of how they see the dynamism of their field and whether they teach functional skills that are apt to change, like coding, or business principles and best practices, which are more stable.

\section{The Question of Leveraging Non-Proprietary Content}

Despite concerns over textbook cost, interviewees were generally not aware of strategies they could leverage to rely on non-proprietary content, such as zero cost textbooks or 
other open content. As one instructor noted, “Unfortunately, far fewer people are aware of these things than I would like. Every now and then when I'm talking to somebody working on the curriculum or syllabi, I'll tell them 'Did you look at Books 24x7? ${ }^{13}$ The book might be available or another very similar book might be available.' Many of us don't know that." A willingness to adopt, or at least consider, such resources appears to exist, but requires greater outreach and awareness building among instructors.

It is important to note that while cost was a significant concern for instructors, generally this consideration was held with respect to students and did not necessarily extend to the library or the institution. For instructors, "free" resources generally meant those that were no cost to students, whether or not the library paid for them. Nonetheless, opportunities exist for moving beyond reliance on proprietary teaching materials, including open access resources. Some institutions are already moving in this direction: MIT's Sloan School publishes open access cases under the Creative Commons license, as does the University of Acadia in Canada. Virginia State University's School of Business reworked its curriculum in 2010 to include open textbooks with improved student outcomes. ${ }^{14}$ One potential benefit to this direction is the ability to incorporate more and different voices, perspectives, and topics than those covered or put forth by the major publishers. HBS cases, for example, have been criticized for undue emphasis on American examples, not sufficiently representing women leaders, and ignoring certain business issues, such as labor unions. ${ }^{15} \mathrm{~A}$ large, diverse community of creators contributing to the canon of business course materials could help to remedy these shortcomings, providing more diverse perspectives and business situations. Furthermore, while the case method is a very well established element of business education, there has been a recent push to innovate. Yale's School of Management, for example, has developed the "raw" case method, which is more open-ended and includes more diverse media than traditional cases. ${ }^{16}$

The need to keep pace with the business world was a recurring theme for interviewees, and the speed of change and need to provide students with current information and

\footnotetext{
${ }^{13}$ Books $24 \times 7$ is a product of Skillsoft, a cloud based provider of learning and performance support resources. Books $24 \times 7$ provides business, technical, and engineering content, generally through a library subscription.

${ }^{14}$ Andrew Feldstein et al., "Open Textbooks and Increased Student Access and Outcomes," European Journal of Open, Distance and E-Learning, 2012/II, http://www.eurodl.org/index.php?p=archives\&year=2012\&halfyear=2\&article=533.

${ }^{15}$ Andrew Jack, "Why Harvard's Case Studies Are Under Fire," The Financial Times, October 2018, https://www.ft.com/content/0b1aeb22-d765-11e8-a854-33d6f82e62f8.

${ }^{16}$ See further explanation from the Yale School of Management, https://som.yale.edu/faculty-research-center/case-research-anddevelopment.
} 
cases stand as major challenges to the viability of non-proprietary content over the longterm. ${ }^{17}$ For example, one interviewee noted, "I keep dynamically changing it [the syllabus] as well, because. .you have to update as and when new concepts, new companies, or new phenomena are around. So the syllabus changes about every three years. There's a 40 percent turnaround of the content." The need to constantly update materials seriously complicates any effort to solely rely on non-proprietary content alternatives such as OERs and individually generated case studies, and will likely require a much greater scale of collaboration, information sharing, and buy-in than currently in place. A further consideration is the data upon which a case study is based. Instructors may rely upon personal relationships with industry to acquire proprietary data for their classes or utilize their own research data to write cases. In these circumstances, instructors may be constrained in their ability or willingness to share their materials. ${ }^{18}$ Creating non-proprietary course materials in fields that heavily rely on data may therefore be especially challenging.

\section{"Without some sort of computer-assisted grading, I think it'd be impossible to regularly assign homework... and expect them to get any sort of timely feedback on it."}

Another consideration for the adoption of non-proprietary content in business education is the extent to which instructors rely on close integration between textbook, assignments, and learning management systems. Numerous interviewees noted that they used assignments provided by textbook publishers in their classes (though there was generally less utilization of slide decks provided by publishers), McGraw Hill's Connect platform being an oft-cited example. Through Connect, students can access their textbook and assignments, and instructors can use the platform to grade and, to some extent, obtain analytics on their students. ${ }^{19}$ As might be expected, instructors relied heavily on the grading functionalities of these systems in larger introductory courses, as

17 Julia E. Seaman and Jeff Seaman, "Freeing the Textbook: Educational Resources in U.S. Higher Education, 2018," Babson Survey Research Group, 2018, http://www.onlinelearningsurvey.com/oer.html. See esp. p. 33, "OER in business seem to be consistently outdated and in some cases inaccurate. Faculty have tried unsuccessfully to implement them into their courses. At times OER has significantly impacted the student experience."

${ }^{18}$ Howard Thomas, Peter Lorange, and Jagdish Sheth, The Business School in the Twenty-First Century: Emergent Challenges and New Business Models (Cambridge: Cambridge University Press, 2013), p. 3, doi:10.1017/CBO9781139012119.

${ }_{19}$ See "Grading and Recording, McGraw Hill, https://www.mheducation.com/highered/connect/grading-and-reporting.html. 
one instructor pointed out, 'Without some sort of computer-assisted grading, I think it'd be impossible to regularly assign homework. . and expect them to get any sort of timely feedback on it." As reliance on integrated systems like McGraw Hill's Connect is only likely to grow, non-proprietary content must be able to function in a similarly integrated manner if it is to be widely adopted.

\section{Beyond Cases and Textbooks}

The issue of currency is often addressed by relying on less traditional course texts, especially news and magazine articles and, occasionally, scholarly articles. Reliance upon these sources resolves two problems: the need to use current information and to engage students. By assigning articles about recent events, instructors express greater confidence that their students will read and engage with the text and the underlying business issue it presents. As one interviewee explained, "We use current events a lot, incorporating that in with the material. That's how we start every class in terms of the news articles that relate to the subject matter that we are dealing with so that they could see that everything relates to everything else. It kind of like pumps them up gets them started in terms of participating in the other lecture content."

\section{"I don't use academic articles, I use industry-written articles. So it's essentially 'how to do' by a practitioner, not by an academician."}

Similar to the use of professional reference works noted above, instructors may assign professional publications, such as trade magazines or association publications, to their students. Instructors rely on this type of material to keep in step with current trends and practices. Instructors recognize an added benefit in such resources in that they allow students to act as a professional would in their field, thus providing them with a practical experience. As one instructor explained, "Some of the faculty who are teaching in this course, they use textbooks. ... To be honest with you, articles are much more up to date, and more relevant. And I don't use academic articles, I use industry-written articles. So it's essentially 'how to do' by a practitioner, not by an academician." interviewees frequently singled out The Wall Street J ournal, The Financial Times, The Economist, and The New York Times as crucial sources for acquiring general, current information, and frequently use these sources as the basis of in class discussions. 
Access to these sources is a significant concern, however. Instructors often use their own subscriptions to these sources, but they cannot rely on or expect their students to have personal subscriptions to myriad sources such as The Wall Street J ournal or The New York Times. Generally, instructors seem unsure whether their institutions offer access through their libraries or if their students will have success in accessing articles at a later date. For example, some instructors did not know if a link they posted in their institution's Learning Management System (LMS) would work, or if it was possible to provide a link that would take students through their institution's proxy server. As changing budgets force libraries to constantly update their subscriptions, some instructors felt they did not have a solid grasp of what the library currently offered. As one instructor said, "One of the challenges is just knowing what's available.. As the library's resources change, just staying up to date and current with that is important." Of greatest concern and anxiety, however, was the issue of copyright and fair use, and instructors expressed the need for guidance on the legality of distributing materials from these sources to their students.

\section{"One of the challenges is just knowing what's available...As the library's resources change, just staying up to date and current with that is important."}

The proliferation of online video content has also become a valuable resource for instructors in their struggle to keep their students engaged. The difficulty of discovering relevant, current videos and finding a reliable way of accessing and assigning them were commonly expressed obstacles in this regard. As one instructor explained, "I used to have students watch movies for class. They said that that was the hardest part, getting access to the movies." For this reason, several interviewees expressed interest in the creation of a curated archive of video materials, in the 5-20-minute range, for use in their classes. YouTube was the most commonly used platform to discover videos, while TED Talks and shows like Shark Tank were frequently mentioned as useful content. Other video content, such as 60 Minutes or video from a company's website, were also noted as commonly used material. Kanopy was referenced as a video resource, though its expense proved a significant barrier to reliable access. As with news articles, significant confusion and anxiety over copyright surrounded the use of these materials in class, and instructors are generally concerned whether videos they include in their syllabi will still be accessible a few months later. Despite instructors' highly positive view of video, they typically use video content only on an ad hoc basis because of these issues and concerns, incorporating material only when the opportunity to do so arises. 
Creating and curating content can thus require significant amounts of time, energy, and resources on behalf of instructors, though this effort is not necessarily without reward. Regardless of what professional rewards accrue to individual instructors, one interviewee noted that innovative teaching and program development can lift the profile of an entire school: 'We're Midwest and they don't expect cool stuff to come out of [this university], to be quite honest with you. So, when we're out presenting and doing and showing stuff that we do here, it really turns their head. So, we're proud of that fact." Effectively leveraging the work business instructors already do-through sharing case studies as OERs, for example - has the potential to yield tangible benefits for business programs, attracting greater attention, prestige, and students.

\section{Effectively leveraging the work business instructors already do-through sharing case studies as OERs, for example- has the potential to yield tangible benefits for business programs, attracting greater attention, prestige, and students.}

\section{Information and Data Practices}

Undergraduate business students conduct industry research, produce marketing material, consult for real companies, create and analyze diverse sets of data, and more. However, instructors often find their students' skills in these areas to be lacking, and are at a loss as to how to address the wide range of skill levels they see in their classes. Moreover, the changing demands of the business world also put pressure on instructors to keep their own skills and competencies current. From providing instruction, access to data, or workspace, libraries have a key role to play in supporting the information and data practices of both instructors and students, though its resources are often underutilized. Of particular note was the use of the one-shot library class and the clear need to better communicate the goals, potential, and limitations of the library's teaching services in instruction in information literacy. ${ }^{20}$

\footnotetext{
20 The "one-shot library class" is a common form of library instruction. In this case, we mean a single class session led by a librarian with the goal of instructing students in a pre-defined range of subjects, typically library resources, research methods, or other information literacy related topics.
} 


\section{Why Business Students Need Information Resources, Tools, and Spaces}

Business students must undertake a variety of research tasks, and though they may be assigned to write research papers, more often they will need to conduct research as a part of a project or case study. Such applied learning is a major component of business education, and can require a high level of diverse skills and information literacy. For advanced students, or those taking a capstone course, projects can require site visits, consultation with clients, desk or industry research, presentations, data analysis, and more. For example, in a statistics class one student project looked at the practices and cost of printing at their university, while in another, students studying operations management were required to work with a company to identify how business concepts were actually being applied in the real world. Projects in management may require students to develop a fictitious company and figure out real suppliers, vendors, and create promotional material, while those in marketing may be required to develop marketing solutions for a real company the instructor is working with. The projects business students work on can be exceedingly diverse, and while access to industry data (discussed below) is an essential component, students require a variety of supports to ensure their project's success.

\section{"I think the library is increasingly more a place of actual personal interaction...for study groups with the resources always nearby and the free access."}

Instructors see the ability to work effectively as a group as a vital skill that students will need in the workplace. While individual projects are not uncommon, interviewees tended to focus on the team projects they assigned their students. Interestingly, it was in the context of these team-based projects that instructors often cited the importance of the library as a student resource. Though students can access the library's research and data resources without ever setting foot in the physical confines of the library itself, instructors noted that the spaces libraries offered for group work were vital. As one instructor noted, "I think the library is increasingly more a place of actual personal interaction.. for study groups with the resources always nearby and the free access." Beyond study space, business students are likely to need space where they can practice giving presentations with their teams, potentially even needing to record themselves doing so, as well as access to video conference equipment or other technological services that allow them to connect with industry partners or clients in a professional setting. 
In a field like marketing, instructors may task their students with developing an entire promotional campaign for a real or fictitious company, and in these cases, students must not only research their company and its industry, but also create content. Students may develop social media campaigns, produce videos to post to YouTube, or create a variety of printed or digital marketing materials. In these cases, students are likely to rely heavily on campus resources to gain access to editing software and to learn how to use it. The sheer variety of student assignments and outputs requires close collaboration between instructors and institutional resources like the library. Though it may be impossible to anticipate all of the needs of instructors and students (and occasionally, clients), it is useful to focus on two fundamental though related issues: information and data literacy.

\section{Research \&Information Literacy}

When trying to understand how and when research skills are taught to students, it is important to think holistically about students' education. There was a noticeable disconnect between interviewees concerning when students should learn to conduct research. For example, several interviewees expressed dismay that their students did not come to their upper level classes with the necessary research and writing skills, expecting them to have learned these skills in lower division classes. Thus one interviewee: "In their project, they have to collect data and since this is a 200-level course, I'm assuming they have already learned how to do basic research and where to find it. At this point, when they write their report, I expect them to know how to cite, how to go to a legitimate source without making up numbers." However, instructors of lower division classes often do not see their courses as the appropriate venues to teach these skills, focusing instead on the provision of essential content and concepts upon which they expect their students to build in future coursework. As one interviewee noted, "The foundational learning isn't there for them even to be able to do really the harder research." There is thus confusion over when basic research skills should be taught and who should do it, with a general expectation that someone else has done or will do it. The library is often involved in this discussion through the one-shot library class, though the effectiveness of this model varied widely.

A related challenge encountered by instructors is the diversity of knowledge levels and research skills manifested in their classrooms. Prerequisites notwithstanding, students often take multiple pathways into a course, and this can be true of both introductory level courses as well as upper level electives, and some instructors noted a wide variety in student skills and awareness of campus resources, and were at a loss as to how to get their students on the same page. A similar heterogeneity may exist surrounding students' analytical skills, especially with respect to technical ability with programs like Microsoft Excel. Some students may start college already quite familiar with standard platforms 
like Excel while others may not. This, of course, puts those latter students at a disadvantage, and this is compounded by the fact that the basics of using these platforms are not always, or even regularly, taught in class anymore. As one instructor explained, 'We aren't teaching them clicks anymore [i.e. how to use the software]. They should have learned the clicks at home, and by the time they come here they're solving a problem that we give them."

To bring students' technical skills up to speed, instructors may rely on services like Coursera and Lynda.com (now LinkedIn Learning) to teach their students "clicks" so that class time can be used for higher-level analysis, problem solving, and discussion. While teaching "clicks" is a domain of learning well suited to video or online instruction, there nonetheless exists significant space to support students who need to learn these essential skills.

\section{Students' comfort with navigating the digital environment does not necessarily translate into an ability to find quality information, and they may not understand that the information networks they are most familiar with are not always appropriate sources for research.}

Instructors hold diverse views on their students' ability to discover information. Because students have come of age in a radically different information environment than most of their instructors, some instructors were impressed by students' ability to navigate the online information environment and quickly pick up new digital tools. On the other hand, many interviewees noted that students' research abilities were generally shallow, relying exclusively on Google's search engine, and that students did not generally try to find better sources less conveniently available. Students' comfort with navigating the digital environment does not necessarily translate into an ability to find quality information, and they may not understand that the information networks they are most familiar with are not always appropriate sources for research.

Like in many other disciplines, discovery of sources and discernment between them is a major point of concern among instructors. Because Google is the first, and often only, discovery tool students use, it may take them longer to find relevant, quality sources than if they began from a more tailored search engine like the various discovery tools and databases offered through the library's website. 
Access is also a challenge. Beginning from Google may also mislead students regarding the resources they have access to, hitting a paywall when, in fact, they have access through the library. This is especially true if they are not on their campus Wi-Fi network or proxy server. The result is that students are hampered in their research efforts in primarily relying on Google, as one instructor noted, "Not understanding the access to the databases that they have now is crazy and it's actually handicapping them somewhat."

\section{"Not understanding the access to the databases that they have now is crazy and it's actually handicapping them somewhat."}

To address some of these challenges, many instructors noted their reliance on their library's resources, often referencing a class spent with a librarian reviewing research practices and library resources. Instructors rely on such sessions to provide basic instruction in research practice to their students, but it is not clear how effective this model is. While instructors believed that students benefited from learning about the different resources offered through the library, they expressed doubt as to how much of this information was retained by their students, or later utilized when actually assigned to research. One instructor recalled, "We have this wonderful session, the research librarian comes in and literally has it personalized to their assignment how to' - you go here, and you click here, and look at this, here's how you do a search.. A week later they're like, 'What? I have to do this research assignment?' I feel like I keep having to start over."

Critiques of the "one-shot" library session model are common in library scholarship, as are explorations of the relationship and division of labor between instructors and librarians in information literacy instruction (tellingly, instructors are generally unfamiliar with the term "information literacy," though more comfortable talking about data literacy and research skills). ${ }^{21}$ Ironically, the one-shot model can in fact hinder students from developing information literacy if instructors believe they have been

\footnotetext{
${ }^{21}$ See for example, Claire McGuinness, "What Faculty Think — Exploring the Barriers to Information Literacy Development in Undergraduate Education," Journal of Academic Librarianship 32, no. 6 (Nov. 2006): 573-74; and Heidi LM Jacobs \& Dale Jacobs, "Transforming the One-Shot Library Session into Pedagogical Collaboration," Reference \& User Services Quarterly 49, no. 1 (2009): $72-82$.
} 
relieved of this pedagogical onus by the library. In instances like those described above, instructors may think that by including a session lead by the library, they have successfully outsourced the job of teaching information literacy and research practice. As one instructor responded, "the whole project. . is research based. And myself, I do not teach them how to. Lucky for me, I have relied on you [business librarian] over the years to teach them through the orientation, and teach them how to use those databases." In such cases, instructors may think they have done due diligence in teaching their students to research through this one-shot model, rather than understanding that inculcating information literacy is an ongoing process. This is not to say that such sessions are necessarily unhelpful, however. One interviewee observed a decline in the quality of student research during summer classes when the librarian was not available, for example. Thus, while the pedagogical utility of the one-shot library class model may be mixed, it is clear that both librarians and instructors must be clear on what the class is meant to accomplish, as well as its limitations.

\section{Finding \& Accessing Data}

A closely related issue to students' research skills is their ability to find and work with data. Access to data is an overriding concern for business instructors and their students, as one instructor put it, "As business professors, we need databases, because you can't do a lot without databases." Common data sources that business instructors work with include Data.gov, Eikon, Bloomberg, Wharton Research Data Services (WRDS), Yahoo! Finance, CRSP/Compustat, the IMF, Kaggle, MarketLine, IBIS World, EDGAR (SEC), Census.gov, World Bank Open Data, and Data Market. However, even when exploiting all of these sources, data can be hard to come by, and access to industry data can be especially difficult to obtain, even for instructors. Introductory classes in data-heavy fields may rely on databases included with the course textbook instead of requiring students to discover data on their own, while in more advanced classes finding and working with data is frequently necessary. Though data is essential to most areas of business education, securing access to relevant data is a major concern.

By nature, business education relies on a wide variety of data sources, from public census data to private company data, and providing access to sources representing the diverse range of instructor and student research interests is a difficult task for even the bestfunded institutions. Because of these limitations, instructors take a range of approaches in teaching their students to discover, access, and work with data. As one interviewee summed up, "We don't have money to buy the data-we improvise." Like the discovery of other information, Google was often the first stop for both instructors and students, though some interviewees noted their classes heavily relied on the library website to access databases. Reliance on the library's data resources was more commonly noted when students were trying to access a specific resource they knew was there, usually 
because it was pointed out to them by their instructor or a librarian. The library was therefore seen less as a place of discovery than as a provider of access to data resources identified by other means.

\section{By nature, business education relies on a wide variety of data sources, from public census data to private company data, and providing access to sources representing the diverse range of instructor and student research interests is a difficult task for even the best-funded institutions.}

Though less commonly used for discovery, the library nonetheless plays a critical role in providing access to data. However, as noted above, a significant challenge for students (and instructors) is not knowing what databases they have access to through the library, especially when they are not specifically pointed to a particular resource. Some interviewees noted the value of their business librarians speaking to their classes about their institution's data resources, while others wished for greater communication between their departments and the library in this regard. Indeed, instructors often saw increased communication over data resources as desirable since they felt they were not always aware of what the library currently offered. One interviewee requested a link or list of resources that instructors could post to their course websites as a simple reference that could both help students and be easily updated when necessary. Finding similar ways to raise student awareness of the databases available to them are therefore vital to leveraging the library's resources to greater effect.

Beyond the library, instructors take a variety of approaches in helping their students find and access data. In some cases, instructors may walk their students through downloading a data set and analyzing the information in class. In more advanced classrooms, students may be expected to find datasets on their own and figure out what questions to ask of them. In one example, students were asked to make a five- to tenminute pitch explaining their research question, the data they found to address it, and how they were going to approach answering their question. This model appeared to be highly effective as it forced students to discover data on their own while also providing an early check to ensure their project was properly scoped and feasible. In a similar exercise, students presented the project they hoped to work on and then crowdsourced ideas for data sources from the class. Of course, instructors also help direct their students toward relevant data sources, either directly or by recommending other 
instructors with better command of the subject area. However, some instructors expressed reluctance to give data directly to their students, especially more advanced ones, seeing pedagogical value in forcing their students to find data on their own.

Because of limited budgets, many institutions cannot provide students access to all desired data sources, even some widely used commercial business databases. Since access to industry data is expensive or otherwise difficult to come by, both instructors and students often rely on publicly available data from the government, United Nations, or other public sources, with the US Census Bureau being a commonly cited source. Other sites, Data.gov for example, publish government data free from copyright, and the sheer amount of data provided through these outlets gives instructors ample material to work with.

Unfortunately, just because data is publicly available does not necessarily mean it is easy to find or that government websites are easy to navigate. As one interviewee recalled, "The Bureau of Economic Analysis, they have tons of data, but.. it takes a little bit of working with it to understand how you get to the right place and to select the data that you need.. I think that the students found it hard." Thus, though the number of data providers may be vast, most courses rely on public data, and libraries may well focus their efforts on showing students how to navigate the government's (admittedly also vast) data ecosystem. Indeed, some instructors saw research efficiency as a crucial lesson provided by the library. As one interviewee noted, "That's where you guys at the library play a key role, teaching them to be more efficient doing that research."

Though public sources of data are the most often used for instruction, private or industry sources also play an important role. However, these sources may prove unreliable over the long term, as they often rely on personal instructor relationships or a funding model that libraries may find difficult to accommodate. Bloomberg and Eikon, are common sources of industry data, and in fields like finance, exposure to Bloomberg's data, and the Bloomberg Terminal, is important professional training. Reliance on such sources should not be taken for granted, however. USADATA, a marketing consultancy based in New York, is one example of a company that formerly worked with universities to provide data for educational purposes. This relationship abruptly changed, however, as one interviewee explained: "USADATA.com is one of the topnotch providers. Their databases are so clean, so up-to-date, and so comprehensive. But the trouble is the director told me, 'We're not gonna work with [university] students anymore."' Some interviewees expressed concern that the industry in general was moving in this direction. Another instructor noted, "We used to get lots of data free. But now everything you have to purchase, you have to use these and we are having issues with public information. Which is now becoming private. . I assume [the data] should be public information but now, it's more private. And that is a problem." Other interviewees recalled working 
directly with companies to obtain data for their classes, only for the company to pull out at the last minute. Ensuring access to a diverse range of databases and data providers also is therefore one of the most intractable problems facing business educators.

\section{"We used to get lots of data free. But now everything you have to purchase, you have to use these and we are having issues with public information. Which is now becoming private...I assume [the data] should be public information but now, it's more private. And that is a problem."}

Although interviewees held generally positive views of the library as their partner in this regard, the library's services are often underutilized. Thus one interviewee: "It'd be nice to integrate [the library] a little bit more, especially for areas involving information or data access to these tools that the libraries may have." Access to data is, therefore, a crucial issue on which greater collaboration between libraries and instructors might yield fruitful results.

\section{Working with Data}

Getting hold of data is not, of course, the end in and of itself. Students must learn to manipulate, analyze and interpret the data, for which they need instruction in a variety of technical areas. Teaching these skills, however, can also be a challenge. Technical platforms and coding languages can change with remarkable speed as the market changes, and instructors often feel they do not have sufficient support to keep their own skills current.

In addition to discovering existing data, instructors and students may also create their own datasets for classes. For example, in advanced classes that involve coding techniques, students may be asked to write programs that can scrape information from the open internet. In these instances, instructors were concerned not with their students finding access to data, but with how their students were managing it. Instructors noted that their students collected a host of different kinds of information, but were unclear as to how their students were storing it. Some thought their institution provided some sort of data hosting service for students, while others noted their students primarily relied on 
Google Drive to store and share their data. Though data storage and management was less an overall concern for interviewees than data discovery and access, for some courses, addressing data storage and management resources may be equally as important.

Students discover, access, manage, and store data, but the final and most important way they engage with data is through analysis and manipulation. As already discussed, some instructors are moving away from teaching "clicks" in class, instead reserving class time for higher level analytical activities. This disinclination to teach analytical tools like Excel contrasts with instructors tending to take a more direct hand in teaching coding. For example, many interviewees mentioned the development platform GitHub as an important resource for them to share and collaboratively work on code with their students. The programming languages instructors teach vary widely and are generally dependent on what they themselves have learned. Some instructors expressed a desire for greater institutional support for instructors to learn new programming skills. Such support for instructor development can be critical, as they must constantly respond to the changing demands of the market. For example, one interviewee noted that their accounting department recently had to implement courses on the R programming language as it was becoming increasingly popular ( $\mathrm{R}$ is free and open source). While Stata was previously used for econometrics and other statistical analysis, the interviewee noted that the industry was moving to R and RStudio (R's software environment).

There is real urgency in implementing such changes: producing graduates without desirable skills can diminish the value of a program's degree and the reputation of the business school. In the above example, it was alumni from the accounting program who advised the shift to $\mathrm{R}$. The interviewee explained, "I hear from the Accounting Department that their biggest complaint has come through alumni who come backwho come back to tell the Accounting Department 'you're falling behind,' or 'your students don't know R.'” The need to keep pace with industry, therefore, is not an abstract concern for business schools - it is a real and immediate imperative with direct consequences for the school and its students.

\section{Significantly, though instructors often saw the library as a partner in student instruction, they tended not to think of the library when considering their own learning needs and professional development.}


Because data is so central to business instruction, instructors themselves need support for data skills at a variety of levels, even in fields less reliant on technical coding skills. For example, one interviewee noted, "I would like to know how to use [three] big tools, Python, R, and Tableau...so any resources that kind of helps, you know, like a non-native Python, non-computer science person." Other instructors may not need rudimentary instruction, but rather to update their skills to current industry standards. Recognizing these issues, some departments are attempting to budget funds for instructors to receive training and update their technical skills. Online course delivery platforms like Coursera and Datacamp were cited as ways instructors could learn new skills and brush up on others. Websites such as Stack Overflow, a coder community website where users can post questions and receive answers, was also cited as a resource for business instructors to improve their coding proficiency. Significantly, though instructors often saw the library as a partner in student instruction, they tended not to think of the library when considering their own learning needs and professional development. While centers for teaching and learning may provide more general pedagogical support, business instructors need more specific teaching and learning support centered on data and technical skills.

\section{Leveraging Technology in the Business Classroom}

Instructors rely on their institutions' learning management systems (LMS) to distribute course materials to their students. They also increasingly rely on their LMS and a variety of other technologies to engage students, assess their performance, and solicit student feedback. The technology used in the business classroom varies widely, but might include PowerPoint, Top Hat, Lucid Chart, iClicker, Kahoot!, Socrative, Google Docs, Google Sheets, Learning Catalytics (Pearson), Poll Everywhere, Remind, and GroupMe. Such technologies play an increasingly important role in large introductory classes, where large enrollments and few TAs make grading, engaging, and otherwise keeping track of students a substantial burden. The adoption of these technologies in the classroom also opens up significant potential for the collection of student data, though instructors were generally deeply ambivalent about the use of learning analytics.

\section{Learning Management Systems}

Instructors teaching in business fields provide course materials principally in digital formats and make extensive use of their institution's learning management system to distribute them. Most interviewees eschewed the idea of creating a course website separate from the LMS, finding it to be needless extra work, or even a bit passé. The course's LMS site, then, is the main portal through which students digitally access their course, whether the course is primarily face to face or online. While instructors heavily 
rely on the LMS, these systems are not without their problems or frustrations. For example, several interviewees noted a steep learning curve when first adopting the LMS or when their institution upgraded to a newer version. Here, institutional supports proved vital, as several mentioned taking seminars to learn how to use the LMS. Some uncertainty remains, however, as several interviewees noted confusion when migrating materials from one year to the next. A few instructors were also uncertain how effectively their course's page was set up, noting student confusion, and wished a support service existed that could look over their page for clarity and accessibility. A related concern was that each course tends to use the LMS in a slightly different way, and this variance can cause confusion for students when they interact with the platform across several classes.

Business instructors also rely on their institution's LMS to communicate directly with students and to allow students to communicate with each other. Blackboard's Collaborate, for example, can allow students and their instructors to web conference or hold virtual office hours. Since group projects are often a major component of business education (see above), this functionality can be critical for student collaboration. Instructors also saw the chat or blog features of their LMS as a way to allow more students to participate in class discussions, especially for those students who may be reticent to speak in person. For business programs that offer courses online or are geared toward distance learners, the communications capabilities of these systems are especially important in facilitating student interaction and collaboration. As one instructor explained, "They [students] prefer to meet me online than to come to campus. They have to find parking, come into the office, and if they're having issues, sometimes they can just dial in, 'I need some help.'”

Most learning management systems offer more advanced features for student assessment and metrics, but, when available, these features were unevenly adopted. Some instructors reported utilizing these platforms' ability to track student engagement with course materials, including whether they opened a file or how long they spent with an assigned text. These instructors are in the minority, however, and the majority of interviewees noted being nebulously aware of these functions, but did not express enthusiasm for adopting them. Interviewees were similarly ambivalent about using these systems to track students who may be struggling or insufficiently engaging with the class.

While some interviewees expressed reservations over the collection of this kind of student data, most did not express concern when asked. Interestingly, interviewees tended to shift to speaking about teaching their students business ethics and related privacy issues in the private sector when this issue was broached. It would seem, therefore, that business instructors do not, in the main, devote considerable thought to student data issues, though these issues are often similar to those of industry. Indeed, library-led projects like the Data Doubles project are specifically exploring this issue 
from the student's perspective, but it is important to note here that instructors themselves do not appear to be too concerned with this issue.22 Furthermore, some instructors who have access to this data were not always sure how to interpret it. For example, if a student spent a long time looking at a page, does that mean it was challenging for them, or that they just left the page open, and is the system able to correct for the latter scenario? Confusion over what the data actually means can therefore be a significant barrier to its effective use by instructors, and may discourage them from using the data at all. Nonetheless, instructors who did wish to use this data to improve their teaching did not insist on having access to individual student data. Most who were interested in the possibilities of student data noted that having aggregate class data could help them improve the structure and planning of the class, even if they could not tailor their teaching to help students individually.

\section{Most who were interested in the possibilities of student data noted that having aggregate class data could help them improve the structure and planning of the class, even if they could not tailor their teaching to help students individually.}

In addition to their university's LMS, instructors often rely on the integrated platforms provided by textbook publishers like McGraw Hill and its Connect platform. In some instances, these systems can effectively replace an institution's LMS if a majority of the class's content and assignments are provided through the publisher. In other cases, these systems are able to integrate directly with the institution's LMS. The principal benefit noted by instructors was that the platform offered students a single point of entry for the class, containing readings, assignments, tests, and other materials. Excellent customer support was consistently pointed out as a benefit to instructors using these particular platforms as well. Connect can also provide student metrics much like other learning management systems, though unlike an institution's LMS, it cannot track students across all courses.

22 See the Data Doubles Project website for more information, http://datadoubles.org/. 


\section{Engaging Students through Technology: Opportunities and Pitfalls}

Increasing student engagement was the most commonly voiced concern across those interviewed. Some lamented their students' unwillingness to read anything longer than a few pages, while others noted how their students were distracted by technology, principally their phones, in the classroom. Attitudes towards cellphone use was especially mixed, as some saw it as a source of distraction while others noted the potential to engage their students through the devices that are already ubiquitously present in their lives.

As noted previously, video was the most common resource instructors used to engage their students. As one instructor recalled, "As soon as I say we are going to watch something they perk up, even if it's the most boring Harvard Professor. It's unbelievable. I mean the guy's much more boring than I am... but it's on a screen. It's like, I always thought maybe I should do a lecture and not be there. J ust be on the screen. They will be overjoyed." The most fundamental technological affordance for engaging students in the classroom is, therefore, the ability to play video.

A majority of the instructors interviewed were also interested in, or were already using, technologies in their classes beyond video and their institution's LMS. Platforms designed to increase student engagement and participation in class were especially popular. Kahoot!, Top Hat, and iClicker were mentioned numerous times as ways to increase student engagement. The most common use for these systems was to set up inclass polls or mini quizzes (generally anonymized or not graded) to gauge student comprehension. For example, in a finance class, students would be posed a question and then required to use Excel to come to the right answer, which they then input using one of the above technologies. The instructor can then see how the class performed, explain how some might have come to a wrong answer, and show them the correct methodology. Other instructors, for example in marketing or business ethics, used these technologies less for assessment and more like straightforward opinion polls. Instructors found the ability of these systems to allow students to voice opinions anonymously an advantage, and a way to show the students themselves the range of beliefs and opinions held by their peers.

While instructors generally had positive views of these technologies, there was also concern, among both instructors who did and did not use these systems, of entertainment taking the place of learning and the class serving the needs of the tool, rather than the tool serving the needs of the class. As one interviewee explained, "I don't want the tool to be the focus. I want the learning to be the focus." Instructors who chose not to use such systems often felt they were too gimmicky, or simply not appropriate for the smaller classes that they tended to teach. Indeed, class size was often mentioned in 
relation to the utility of these systems, with larger classes seen as a better context to deploy these learning aides. In cases where these technology platforms were used for graded exercises, there was also some concern that students could cheat or game the system, or simply guess and end up with a passing grade without really having to engage with the course. Again, this was a concern for larger classes where it is more difficult to track students' individual performance. Thus, while instructors were intrigued by the possibilities of technology to improve student engagement, they also recognize that there is no panacea that will solve this problem.

Balancing entertainment, engagement, and learning was the most common concern voiced by instructors in regards to these systems. However, barriers to accessing them were also reported as a concern. In some cases, students must be able to pay in order to access these technologies for class, and so there is also a question of equity in their use. For example, if instructors use clickers in class, students must be able to acquire one of these devices. At least some institutions may allow students to rent one of these devices through the library, while others may not offer such a service. In one instance, an instructor was reluctant to use clickers as a matter of concern over their cost to students, and was not aware that these could be rented through their institution's library. Some platforms allow students to use their own devices in lieu of a separate piece of hardware (e.g. apps that allow a phone to be used as a clicker), but even these still require students to have a laptop or smartphone, which should not be taken for granted.

Even commonly used and widely available software packages may present challenges, as some instructors may ask or require their students to have the most recent version of, for example, Excel, for both homework and in-class exercises. While students may be able to access the most up to date version on their library's computers (itself an important service), it may not be possible for them to participate in in-class activities if they are not equipped with a mobile device like a laptop computer loaded with these programs. In this case, flipping the classroom may cause some students difficulties if they are unable to purchase the software they need to complete exercises with their instructors in class.

Finally, while instructors had overwhelmingly positive experiences with publishers like McGraw Hill and its Connect platform, their experiences were more uneven when engaging with the sales and support personnel of some other providers. While institutions generally provide purchasing services for faculty instructional needs, it is unclear the extent to which instructors are aware of or receiving this support. For example, some interviewees felt intensely pressured by sales representatives to commit to using a product in their classes, and one interviewee said they were met with hostility when asking for more time to consider. Negotiating with such third party providers is not a common duty that instructors, even business instructors, generally perform, and they likely do not have a comprehensive view of the educational offerings currently available 
at their institutions or in the marketplace. Indeed, several interviewees noted that they actually discovered new learning technologies from their students, and in some cases relied on students to teach it to them. It is therefore important that instructors be made aware of available technology and supported in their interactions with providers so that institutional and student resources are utilized most efficiently.

\section{Taking the Pulse: Assessing Student Skills \& Collecting Student Feedback}

While instructors were ambivalent about using technologies to track individual student performance in their particular courses, they had greater interest in technologies that could afford them a general overview of their class, especially with respect to the uneven level of students' skills. For example, instructors wished to know how many of their students had taken other business or economics classes, or what was the class's general level of proficiency with Excel. As one interviewee explained, "heterogeneity in the classroom and the variance.. of skill sets. . is something to be mindful of." With such information, instructors believe they could better pitch and pace their classes to meet that specific class's general level of knowledge and skill.

Another related desire for feedback was a way to track in-class participation. Instructors repeatedly stressed participation as an important element of student engagement and assessment. Participation is considered a crucial element of the business classroom, a natural consequence of the emphasis on experiential learning, as well as important training for students to become comfortable with sharing their ideas and insights. Participation is therefore emphasized in the business classroom as a way of inculcating the "soft skills" students will need in the real world. However, instructors generally lamented the lack of a sufficiently reliable mechanism to track participation. One interviewee related that they had their TA manually keep track of every student who participated in class, recording the data in an Excel file. An added benefit to using clickers or platforms like Kahoot! or Poll Everywhere was that it could also provide an easy way to track both attendance and participation (though this can also be gamed).

A final word must be said about platform reliability, stability, and IT support, issues that cut across all course technologies from the LMS to clickers. A major reservation among instructors for all of these products was their reliability. Interviewees generally expressed satisfaction with their institution's IT support, but the threat of technology breakdown gave several interviewees pause. Interviewees worried that technological glitches could interrupt any lesson plan that relied too heavily on these technologies and waste precious class time. There is also confusion regarding whom to contact in the case of such breakdowns, whether it is the responsibility of the institution's IT department to address the problem or of the service provider itself. Most interviewees who raised this issue felt their institution's IT department would be unable to help them in the event of a 
breakdown beyond the institution's own hardware systems. Perhaps building off their experiences with sales representatives, interviewees were also ambivalent about having to contact customer support and taking time from busy schedules to troubleshoot. Breakdowns also made some interviewees hesitant to adopt other technologies like smartboards: in one case, an instructor noted that, since there were so few of them in the school, it was too risky to rely on them. The threat of technical failure is always a barrier to adoption, but the split between institutional IT and third party customer support bears special consideration.

\section{Conclusion}

Over the past century, business education has grown at a rate unparalleled in the rest of the academy, and, despite recent drops in MBA enrollment, the business major remains one of, often the most, popular undergraduate majors on college campuses. ${ }^{23}$ Because of this enduring interest in business education, instructors need pedagogical support. This report examines the current teaching practices of business educators, focusing specifically on their development of courses and sourcing of materials, teaching their students to research and work with data, and their use of technology to engage and assess students. Based on these findings, we isolate three major themes that should be of special interest to those who support business education.

\section{Concern over Costs}

Business programs and schools may be a source for-or at least, a center of -wealth at their larger institutions, but this does not necessarily reflect an easier material reality for the majority of undergraduate business students. Similar to other fields, instructors are keenly aware of the financial pressures faced by undergraduate business students. Interviewees in the project discussed the importance of reducing student costs in a variety of contexts, but concern over the expense of course texts was especially notable.

Instructors preferred the ability to assemble course packs and textbooks by picking from a publisher's stock of materials, and this customization ensures fuller use of the text in class. However, while the ability to tailor textbooks to meet instructor preferences can help students get maximum return on their investment, this can likewise hinder the library's ability to provide these resources to the entire student body. As one instructor

\footnotetext{
${ }^{23}$ See discussion by John A Byrne, "MBA Apps Take a Shocking Plunge," Poets \& Quants, August 29, 2018, https://poetsandquants.com/2018/08/29/mba-apps-take-a-shocking-plunge/. More recently, Scott Jaschik, "Understanding the Decline in M.B.A. Applications," Inside Higher Ed, February 4, 2019, https://www.insidehighered.com/admissions/article/2019/02/04/new-data-help-explain-decline-mba-applications.
} 
wondered, "The textbook used to be in the library, but since we customize a little bit of the textbook, I don't think it's available in the library." This proliferation of texts at a course-by-course basis, and the fact that these texts can change substantially year to year as entire chapters are added or dropped, can place significant pressure on library resources, and necessitates close communication between instructors and librarians.

\section{Business instructors are ever on the lookout for case studies appropriate for their classes, but are mindful of the costs they are passing on to their students through case assignments. Identifying ways to mitigate these costs should be given high priority.}

Business instructors are ever on the lookout for case studies appropriate for their classes, but are mindful of the costs they are passing on to their students through case assignments. Identifying ways to mitigate these costs should be given high priority. One option, for example, could be creating a mechanism by which open access cases can be stored and shared, which could significantly ease the burden of discovery and encourage instructors to adopt them in their teaching. While the Harvard Business Review maintains a dominant position in the field, and the selling of case studies has certainly been lucrative, interviewees noted that it is not equally strong in all aspects of business education. Identifying those areas where there is an existing need would be ideal testing grounds for the creation and adoption of such open resources. It is also notable that cases targeted at undergraduates, especially lower division undergraduates, seem to be especially needed.

Considering the broader interest in leveraging the OER model of course content creation and use to ameliorate cost, it is important to be mindful of the specific issues pertaining to OER adoption to the business field specifically. In particular, the need to keep materials constantly up to date is one significant challenge, as is securing and sharing the relevant data. Instructor and student preference for integrated digital learning environments and the requisite need to make OER material platform agnostic is a further challenge, and both libraries and institutions will need to consider if OERs are most the most effective solution. If a shift towards open resources like OERs is the preferred solution, a large community of content creators is likely necessary if the burden of creation is to be distributed adequately and the full range of instructional areas covered. Many business instructors maintain their own personal archives of 
instructional materials and case studies, and many already create their own cases from scratch. Instructors at large, prestigious business schools, such as those at Harvard and Stanford, receive recognition and compensation for the cases they provide to their publishers (HBS's cases are drawn from the school's faculty), and so ensuring some professional benefits for instructors publishing OERs should also be taken into consideration. ${ }^{24}$ For example, as there is already significant interest among instructors for learning different pedagogical approaches to the case study, incorporating opportunities to share teaching experiences and techniques could be an added benefit for instructors willing to participate in such an endeavor.

\section{Data Access as an Entry Point into Experiential Learning}

A hallmark of business education is its emphasis on practical knowledge, and, consequently, more and more business instructors are relying on experiential or applied learning methodologies to prepare students for their careers. The case method is one aspect of this focus, but instructors rely on a variety of activities and resources to approximate the real world. While a variety of supports fall under this category (e.g. supporting alumni engagement or contacts with local businesses), perhaps the most actionable step libraries can take to support their instructors is in the area of access to data.

\section{Both instructors and students struggle to know what data resources their institution provides or the role the library could play in securing access to them.}

Data is critical for many business sub-disciplines; consequently, access to data was a major concern voiced by instructors. Both instructors and students struggle to know what data resources their institution provides or the role the library could play in securing access to them. Some interviewees lamented the fact that as data has become ever more valuable it has become harder to access, especially from private sources. Libraries, whose mission is emphatically about access to information, potentially have a major role to play in this discussion, but too often seem to be a missing partner in this struggle, at least from an instructor perspective.

${ }^{24}$ Of course, an OER model would directly contravene the financial incentive behind the HBR model, which has been highly profitable for the Harvard Business School. 
Industry and financial data is crucial, but, in the age of big data, it is important to consider the varied types of data upon which businesses increasingly rely on for success. While definitions vary, big data is often defined by its heterogeneity, including standard numerical data, but also images, text, and video (i.e. "unstructured data"). Though industry has, in many ways, led the charge in big data analytics, surprisingly few instructors spoke specifically about it. It may be that big data analytics is considered a more advanced topic, better suited to graduate level work and research, but as industry increasingly relies on big data, it is likely there will be a commensurate demand for big data instruction at the undergraduate level. How libraries will support access to these types of big data sets, as well as instruction in data science and other big data methodologies, is still an open question, but it seems likely that business education and research would provide an ideal testing ground for new library services and systems.

\section{Ambivalence over Analytics}

Interviewees were generally not using the data analytics provided to them through their institution's LMS or through other providers, even though the proliferation of in class technologies means more and more student data is being collected. Increasing student engagement is one of the main drivers of this growing use of learning technologies, though both instructors and students often do not realize what personal data they may be giving away in the process. ${ }^{25}$ Consolidation or partnerships in the Edtech industry, such as that recently announced between Moodle and Turnitin, further enhance the likelihood that students will unknowingly relinquish large amounts of personal data, with ambiguous benefits to either instructors or the students themselves. ${ }^{26}$ These issues do not obtain solely to business education, but as institutions of higher learning consider adopting these technologies, the responses given here provide an important perspective as institutions develop policies around the use of various learning technologies.

The technologies just described, coupled with the institution's LMS, can collect and provide a whole host of data about student learning practices, yet again it is important to note that instructors were, on the whole, remarkably ambivalent about this potential. While a few instructors were interested in the power of learning analytics to tailor their teaching and provide more direct support to individual struggling students, most found these systems opaque or just another system to figure out and take up their already

\footnotetext{
${ }^{25}$ A useful piece explaining some of these issues is provided by Sean Michael Morris and Jesse Stommel, "A Guide for Resisting Edtech: The Case Against Turnitin," Hybrid Pedagogy, June 15. 2017, https://hybridpedagogy.org/resisting-edtech/. Though their critique is specifically aimed at Turnitin the issues they raise are broadly relevant to learning technologies as a whole.

${ }^{26}$ See Serena Gill, "Moodle Partners with Turnitin to Integrate SimCheck into the World's Most Popular Learning Platform, Moodle, September 16, 2019, https://moodle.com/news/moodle-partners-with-turnitin/, for the announcement of the partnership.
} 
stretched time. In fact, the kinds of data that instructors seemed most interested in was data about themselves. For example, several interviewees were interested in systems that could tell them more about whether or not their tests were well written, for example, by showing which questions were the most difficult for students.

While instructors generally seem only nebulously aware of the data that institutions collect on their students, students tend to have even less knowledge of the information that is collected about them. ${ }^{27}$ Whether or not students realize the data these technologies collect, they may feel little choice but to use whatever technology their instructor has decided on or risk their grade. Because of the inherent power dynamic of the classroom, the onus must be on instructors and their institution to choose third party providers carefully.

\section{With instructors busy and students unaware, the library has ample opportunity to be a leader on these issues and is well positioned within the structure of the academy to educate and facilitate discussion between instructors and students.}

With instructors busy and students unaware, the library has ample opportunity to be a leader on these issues and is well positioned within the structure of the academy to educate and facilitate discussion between instructors and students. Furthermore, as data privacy is an ever more urgent concern in the business world (recall that many interviewees turned to this issue when asked about student data privacy), collaboration between the library and the business school on this issue may provide interesting insights and a valuable experience for business students, tomorrow's business leaders.

\footnotetext{
${ }^{27}$ Preliminary findings from the Data Doubles project have shown that students do not understand the full range of information that their institutions can collect on them, though much like instructors, they generally did not voice serious concerns about its use by their institution. A notable exception to this point was the sharing of student data with third parties beyond their institution, and, given instructors' increasing interest in and use of third party systems to increase student engagement, both instructors and institutions must give serious consideration to this concern when deciding to use different instructional technologies. See Kyle M. L. Jones, Michael R. Perry, Abigail Goben, Andrew Asher, Kristin A. Briney, M. Brooke Robertshaw, and Dorothea Salo, "In Their Own Words: Student Perspectives on Library Participation in Learning Analytics Initiatives," Proceedings of the Annual Meeting of the Association of College and Research Libraries, April 10, 2019, pp. 269-270.
} 


\section{Recommendations}

\section{Course Development and Material Creation}

Instructors need support in the creation and discovery of course related materials. Access to video, newspapers, and magazines were of special concern and seen as vital to better engage students, and a significant gap exists for the provision of these resources. Especially notable are instructors' concerns over the costs of course materials and their interest in solutions that may alleviate their students' financial burdens. While interest in zero cost courses and degrees is growing, and there is much excitement around the potential of OERs, more work will need to be done to identify the most appropriate solution to alleviate the primary concern over cost.

\section{Libraries}

- Assist instructors in finding low cost and open access materials. Libraries can provide aide to instructors by developing lists or guides of open or low cost educational resources. Offer specific consultations for instructors to help them identify the most appropriate resources. As the adoption of no cost or OER resources can necessitate curriculum or syllabus changes, the library can further act as a hub to connect faculty with instructional designers or other institutional resources to support this change.

- Curate an archive of video content for in-class business instruction. Instructors worry that videos they use in class may not be findable in the future (this is especially true of videos from YouTube) and therefore struggle to incorporate video into their syllabus. Create a reliable archive of video content, perhaps working across several institutions, and work with instructors to maintain the currency and relevance of its content.

- Provide access to news content. Like video, news content is especially valued for providing engaging and current instructional material. Seek out opportunities to work closely with instructors to identify and make accessible the most valuable of these resources. Conduct outreach to make the accessibility of already available resources better known to instructors and students.

- Help instructors understand copyright in the context of instruction. Instructors generally do not understand copyright issues surrounding the news articles or videos they like to use in their classes and need to be proactively engaged on this topic. Develop a mix of services (seminars, video tutorials, pamphlets) that explain copyright, fair use, and other policy issues in the context of the classroom (as opposed to research).

- Position instruction performed by the library in the context of lifelong learning. Students need to develop lifelong professional skills to support their careers. Messaging focused around this tangible value may be helpful in engaging students, especially in the one-shot class model. Work closely with the business school's curriculum to identify intervention points throughout the arc of students' education. 


\section{Academic Leadership (Deans, Provosts)}

- Nurture instructors' development of course materials. Business instructors are putting effort into developing their own materials, especially cases, to ameliorate the limitations of pre-existing offerings. These efforts, however, are rarely supported at an institutional level. Commit to recognizing and rewarding these efforts, especially in support of creating open access course materials.

- Evaluate the potential for OER initiatives in high impact fields. Business, for example, holds immense potential for OER adoption, especially considering the popularity of the major. Programs may wish to look to models like SUNY, CUNY, and the California State University system for models in making courses and entire degrees zero cost. ${ }^{28}$

\section{Center for Teaching \& Learning and IT}

- Help instructors gain access to training in different case related pedagogies. Institutions must strategize on whether to provide funding to instructors to use existing resources (e.g. through Harvard Business School) or to develop local programming in this area.

- Develop supports for the online classroom. Many business schools are exploring the potential of online and distance learning, but instructors often worry about their ability to provide instruction comparable to on campus classes. Work with instructors to identify critical supports needed for online instruction.

- Enable instructors to create and publish their own high-quality digital content. Support instructors in online course development by providing audio/video training, assistance, and equipment. Invest in resources such as video recording and editing services and support instructors in using these resources. Give special consideration to resources that support instructors' ability to manage and control their own content to prevent piracy or misuse.

\section{Societies and Associations}

- Explore solutions that facilitate field wide or industry wide resource sharing. Support and encourage the sharing of instructor-developed materials (e.g. cases), and ensure that sharing content is professionally recognized and rewarded.

- Expand Business education standards to include OER materials. Organizations like the National Business Education Association maintain curricular standards. These can be expanded to include quality benchmarks for educational materials.

- Support instructors' teaching development. Societies are well positioned to create professional networks focused on pedagogical training, resource sharing, and support.

${ }^{28}$ CUNY: https://www1.cuny.edu/mu/forum/2019/02/20/zero-textbook-cost-is-call-to-action-as-ccny-converts-to-open-educationalresources/; SUNY: https://textbooks.opensuny.org/oer-textbooks-success-framework/ \& oer.suny.edu; CSU: https://www2.calstate.edu/csu-system/news/Pages/Affordable-Learning-Solutions-Z-majors.aspx. 


\section{Content providers}

- Make content that can easily integrate into digital learning environments. Instructors prefer content that could easily be loaded into their institutions' LMS, providing one environment where students could do readings, exercises, quizzes, discussions, and more.

- Diversify case studies. While the Harvard Business School is the dominant provider of business case studies, there exists significant opportunity to provide content that is more diverse and international in nature.

\section{Discovering, Accessing, and Working with Data}

Data is the lifeblood of many business fields, and so instructors and students rely on access to data sources for their instruction and learning. Despite its centrality, many instructors and students do not know how to find appropriate data for their needs. The increasingly proprietary nature of data forces instructors and students to be creative with the data they can find. It is not only about finding data, however, both instructors and students need support in developing their technical skills and staying current with changing industry standards. ${ }^{29}$

\section{Libraries}

- Prioritize data availability. Business instructors heavily rely on data for their teaching. As the library considers its evolving budget allocations, data must receive greater prioritization.

- Help instructors and students find publicly available data. Government data is an especially critical resource for instructors, but many instructors note that students often have trouble using it. Libraries should consider providing resources or guides targeted at accessing government data and navigating government websites. The one shot library class can also be leveraged toward addressing this need, as can workshops focused on accessing government data.

- Provide support for instructor and student data skills. Many libraries have begun to build up some expertise and support services for instructors and students as they work with data-this is a crucial period for libraries to determine whether and to what extent they should be the locus of support for technical skills. Convene relevant stakeholders to determine the library's strategic direction in supporting the development and training of technical skills.

\footnotetext{
${ }^{29}$ To explore these data issues more deeply, Ithaka S+R is undertaking two further data related studies, one focusing on teaching data literacy in the social sciences, and the other on research using big data and data science methodologies. Both projects are set to launch in 2020. For more information, see Danielle Cooper, "Announcing Two New S+R Projects on Supporting Data Work," Ithaka S+R, July 29, 2019, https://sr.ithaka.org/blog/announcing-two-new-sr-projects-on-supporting-data-work/.
} 
- Create connections between data librarians, business librarians, and the business school. As data is a central component of business education, both instructors and students need a wide range of data services. Establish a working group of data and business librarians and business instructors to develop and assess data services.

\section{Business School Leadership}

- Make data literacy a core educational requirement of all business students. Data literacy is a vitally important competency for business students, regardless of their specific concentration, yet it is rarely made a central aim of instruction. Commit to ensuring all students graduate with the data skills they will need throughout their professional lives.

- Develop relations with local businesses to create instructional opportunities and encourage data sharing. Increase collaboration between instructors and the office of alumni engagement to make contacts with the local business community. Aside from the practical, instructional benefits these relationships present, they also have the power to help business schools develop unique characteristics based on local contexts and alumni achievement.

- Develop networks of businesses willing to share data for instructional use. Leverage the business school's relationship to the private sector and advocate for greater sharing of data for instructional purposes.

\section{Societies and Associations}

- Advocate for curriculum standards on data literacy. The ability to work with data is a fundamental skill expected of students with a degree in business, yet developing data literacy is rarely specifically addressed as a goal in most curricula. Societies have the opportunity to encourage greater emphasis on this issue through greater curriculum advocacy with respect to data.

\section{Data Providers}

- Support instruction through data access. There exists an enormous appetite for datasets but there are few providers of teaching-friendly, accessible datasets. Create data resources (e.g. datasets) appropriate for undergraduate business instruction.

\section{Tools, Technology, and Other Resources}

Instructors increasingly rely on in-class technologies to engage students and keep track of their progress. Though these tools can help instructors gain insight into where their students are struggling, little thought has been given to the issue of student privacy and the uses to which student data could be put. 


\section{Libraries}

- Continue to prioritize and invest in group-work spaces. Business education prioritizes group work and instructors see the library's ability to facilitate collaborative work as a key library service. Students also rely on spaces where they can meet or teleconference with real business clients in a professional setting. As the library considers the allocation and layout out its spaces, they should prioritize creating spaces that can support these activities.

\section{Center for Teaching \& Learning and IT}

- Assist instructors with the selection of in class technologies (e.g. clickers). Instructors often do not have a thorough understanding of this landscape nor do they have experience dealing with the selection and support of academic technologies for enterprise use. Provide greater support for instructors in selecting the right platforms for class needs and direct them to the appropriate resources for procurement and post-purchase support.

- Establish clear technical support protocols. Technology failure is a major barrier to adoption, and instructors are often unclear about whom to reach out to for technical support. Clearly delineate responsibilities between campus IT and provider IT.

- Provide training on learning-analytics tools. Instructors are aware that some of the tools and technologies they use have learning-analytics components but are often unaware of what these are, how to use them, or how they can benefit doing so.

\section{Faculty and Academic Leadership}

- Develop student data collection and sharing policies. Consider especially what data instructors would actually use, as well as student concerns over privacy. As students are most concerned with their information being shared with third party providers, work with these providers to ensure adherence to institutional data policies, and make sure both instructors and students are aware of what data will be shared beyond the institution.

- Establish policies on the adoption of learning technologies. Textbooks are not the only course related costs students incur. Help instructors think holistically about student costs associated with both text and tech, and determine what technologies will be used in the classroom and set policies regarding what costs will be passed on to students. 


\title{
Appendix 1: Research Teams and Local Reports
}

\author{
Baruch College
}

Ryan Phillips, Louise Klusek, and Charles Terng, "Supporting the Changing Practices of Teaching in Business - Baruch Summary,"

https://academicworks.cuny.edu/bb_pubs/1136/.

\section{Bowling Green State University}

Edith Scarletto, Linda Rich, and Vera J. Lux, "Changing Practices of Undergraduate Business Teaching at BGSU,"

https://scholarworks.bgsu.edu/ul_pub/59/.

Georgia Institute of Technology

Patricia Kenly and Ximin Mi, "Undergraduate Business Teaching and Library Opportunities at Georgia Tech,"

https:// smartech.gatech.edu/handle/ 1853/62012.

\section{Grand Valley State University}

Cara Cadena, Preethi Gorecki, J on J effryes, and Carol Sanchez, "Ithaka S+R: Supporting the Changing Practices of Teaching in Business," https://scholarworks.gvsu.edu/library_sp/63/.

\section{Kansas State University}

Kendra Spahr and Livia Olsen, "Supporting the Pedagogical Needs of Faculty Teaching Undergraduate Business Students at Kansas State University," https:// krex.k-state.edu/dspace/handle/2097/ 40292.

Michigan Technological University

Nora Allred, Lauren Movlai, J ennifer Sams, "Tell Me Your Business: Assessing the Teaching Needs of Undergraduate Business Faculty," https:// digitalcommons.mtu.edu/michigantech-p/694/. 
Murray State University

Ashley Ireland, Dana Statton Thompson, and Brian Bourke, "Examining the Pedagogical Practices of Business Faculty: A Qualitative Analysis to Inform Library Support," https:// digitalcommons.murraystate.edu/ faculty/43/.

North Carolina Central University

Danielle Colbert-Lewis, Karen Grimwood, and J amillah Scott-Branch,

"Supporting the Changing Practices of Undergraduate Business Teaching at North Carolina Central University,"

https://libres.uncg.edu/ir/nccu/listing.aspx?styp=ti\&id=29034.

\section{Providence College}

Heather Williamson, Sarah Edmonds, and Peter Rogers, "Supporting the Changing Practices of Teaching in Business at Providence College." https:// digitalcommons.providence.edu/lib_research/1/.

\section{Queens College}

Edward F. Wall III, J ames Mellone, Qiong Xu, "Supporting the Changing Practices of Teaching in Business at Queens College, City University of New York," https://academicworks.cuny.edu/qc_pubs/358/.

\section{Santa Clara University}

Nicole Branch, Anthony Raymond, and Melanie Sellar, "Exploring the Changing Teaching Practices and Needs of Business Faculty at Santa Clara University," https://scholarcommons.scu.edu/library/206/.

\section{State University of New York at Buffalo}

Erin Rowley, "Examining the Undergraduate Teaching Practices of Faculty in the School of Management," https:// ubir.buffalo.edu/xmlui/handle/ 10477/ 80367.

University of St. Thomas

J ohn P. Heintz, Marianne Hageman, Andrea Koeppe, and Ann Zawistoski, "Supporting the Changing Practices of Teaching in Business: University of St. Thomas Local Report," https://ir.stthomas.edu/lib_staffpub/17/. 


\section{ITHAKA S+R}

\section{University of Texas San Antonio}

Natasha Arguello and Veronica Rodriguez, Supporting the Changing Practices of Teaching in Business: A study conducted in partnership with Ithaka S+R," https://lib.utsa.edu/supporting-the-changing-practices-of-teaching-in-business. 


\section{Appendix 2: Semi-Structured Interview Guide}

\section{Background and Methods}

1. Tell me about your experiences as a teacher [E.g. How longyou've been teaching, what you typically teach, what you currently teach]

- Does your teaching incorporate any particular teaching methods or approaches? [E.g. experiential learning, case method, design thinking, problem-based learning, flipped classroom]?

- Have you received any support/ relied on others towards developing your teaching approach?

- Are there any other supports or resources that you think would be helpful for you?

2. Do you currently teach more general research or study skills in any of your courses? [E.g. finding sources, evaluating sources, data literacy, financial literacy, critical thinking]

- How do you incorporate this into your courses? Have you experienced any challenges in doing so?

- Does anyone support you in doing so and if so how? [E.g. instruction classes offered through the library]

- Are there any other forms of support that would be helpful in doing this?

\section{Working with Materials and Content}

3. What materials do you typically create in the process of developing a course? [E.g. syllabi, course website, online modules, lectures, assignments, tests]

- How do you make these materials available to students?

- Do you make these materials more widely available? [E.g. public course website or personal website, sharing via listserv]

- How you experienced any challenges in creating and/ or making these materials available?

- Do you ever consult with others as part of creating and/ or making these materials available?

- Are there any supports that could help you in creating and/ or making these materials available?

4. Beyond the materials you create in the process of developing a course, what other kinds of content to students typically work with in your courses? [E.g. readings from textbooks or other sources, practice datasets, films]

- How involved are you in how this content is selected and/ or created?

- How do you make these materials available to students?

- Do you make these materials more widely available? [E.g. public course website or personal website, sharing via listserv]

- How you experienced any challenges in selecting, creating and/ or making these materials available?

- Do you ever consult with others as part of selecting, creating and/ or making these materials available?

- Are there any supports that could help you in selecting, creating and/ or making these materials available? 


\section{Working with Tools}

5. Have you considered using and/ or are you currently working with data and/ or analytics tools to understand and improve your teaching? [E.g. dashboard or an app through a course management system, early alert notification system on student performance via email]

- If no, why? (e.g. unaware of such offerings, current offerings are not useful, opposed to such offerings)

o If a tool could be designed that leverages data (e.g. about students) in a way that would be helpful towards your teaching, what data would feed into this and how would this tool ideally work?

o Do you have any concerns in relation to how this data is collected and/ or leveraged (e.g. privacy)?

- If yes, what data and/ or tools have you used and how? To what extent was this useful?

o Do you have any concerns in relation to how this data is collected and/ or leveraged (e.g. privacy)?

o What are some of the greatest challenges you've encountered in the process of using these tools?

o Do you rely on anyone to support you in using these tools?

o Are there any other forms of support that would help you as you work with these tools?

6. Do you rely on any other tools to support your teaching (E.g. clickers, smart boards)? If so,

- What are some of the greatest challenges you've encountered in the process of using these tools?

- Do you rely on anyone to learn about and/ or support you in using these tools?

- Are there any other forms of support that would help you as you work with these tools?

\section{Wrapping Up}

7. If there was a magic wand that could help you with some aspect of your teaching [beyond giving you more money, time, or smarter students], what would you ask it to do for you?

8. Are there any ways that library or others on campus have helped you with your teaching in ways that have not yet come up in this interview?

9. Are there any issues relating to your experiences teaching that you think that librarians and/ or others on campus who support you and your students should we be aware of that have not yet come up in our discussion? [e.g. on the role of the library in supporting teaching, what makes teaching in your specific area of Business or Business more widely that warrants unique support] 


\section{Appendix 3: List of Cited Resources}

\section{Technology Platforms \& Tools}

- GroupMe: https://groupme.com/en-US/

- iClicker: https://www.iclicker.com/

- Kahoot!: https://kahoot.com/

- Learning Catalytics: https:// www.pearson.com/us/higher-education/productsservices-teaching/learning-engagement-tools/learning-catalytics.html

- Lucid Chart: https://www.lucidchart.com/pages/

- McGraw Hill's Connect: https:// www.mheducation.com/ highered/ connect.html

- Panopto: https://www.panopto.com/

- Poll Everywhere: https:// www.polleverywhere.com/

- Remind: https://www.remind.com/

- Socrative: https:// socrative.com/

- Top Hat: https://tophat.com/

\section{Data Resources}

- Bloomberg: https://www.bloomberg.com/professional/product/market-data/

- Census.gov

- CRSP/Compustat: http:// www.crsp.com/products/researchproducts/crspcompustat-merged-database

- Data.gov

- Data Market: https:// www.qlik.com/us/products/qlik-data-market

- EDGAR (SEC): https:// www.sec.gov/ edgar/searchedgar/ webusers.htm

- Eikon: https:// eikon.thomsonreuters.com/index.html

- IBIS World: https://www.ibisworld.com/

- IMF: https://www.imf.org/en/Data 
- Kagglekaggle: https:// www.kaggle.com/

- MarketLine: https://www.marketline.com/

- Wharton Research Data Services (WRDS): https:// wrdswww.wharton.upenn.edu/

- World Bank Open Data: https:// data.worldbank.org/

- Yahoo! Finance: https://finance.yahoo.com/

\section{Cases and Other Resources}

- Books 24x7: https:// documentation.skillsoft.com/bkb/library/index.htm\#30369.htm

- Coursera: https:// www.coursera.org/

- Harvard Business School Teaching Resources: https:/ / hbsp.harvard.edu/teaching-skills/

- Issues in Accounting Education: https:// aaajournals.org/loi/iace

- J ournal of Business Cases and Applications: http://www.aabri.com/jbca.html

- Kanopy: https://www.kanopy.com/

- Lynda: https://www.lynda.com/

- MIT Sloan School of Management Cases: https:// mitsloan.mit.edu/LearningEdge/accounting-finance/Pages/default.aspx

- MIT OpenCourseWare: https://ocw.mit.edu/index.htm 